\title{
Tendencias de la migración interna de la población indígena en México, 1990-2015
}

\section{Trends in internal migration among the indigenous population in Mexico, 1990-2015}

\author{
José Aurelio Granados Alcantar* \\ María Félix Quezada Ramírez**
}

\begin{abstract}
Resumen
Este artículo analiza la migración de la población indígena dentro de los procesos migratorios internos. Se plantean como objetivos: caracterizar el perfil sociodemográfico de estos migrantes, identificar los patrones migratorios predominantes y precisar los cambios que han tenido los estados del país como lugares de atracción y expulsión. Las fuentes de información utilizadas son los microdatos del Censo de Población y Vivienda, 1990, 2000 y 2010, y la Encuesta Intercensal 2015. Como resultado encontramos que, para el caso de la población indígena, el patrón migratorio predominante sigue siendo rural-urbano, y el perfil demográfico de los migrantes es en su mayoría masculino y en edades productivas. Asimismo, los estados de Quintana Roo, Nuevo León, Sinaloa, Baja California y Estado de México se consolidan como las entidades de mayor atracción de migrantes indigenas en esta segunda década del milenio.
\end{abstract}

Palabras clave: México; población indígena; migración interna.

* Profesor investigador de la Universidad Autónoma del Estado de Hidalgo, Área de Sociología y Demografía. Dirección postal: Artículo 115, Boulevard Colosio, 42084, Pachuca, Hidalgo, México. Correo electrónico: joseg@uaeh.edu.mx

** Profesora investigadora de la Universidad Autónoma del Estado de Hidalgo, Área de Sociología y Demografía. Dirección postal: Artículo 115, Boulevard Colosio, 42084, Pachuca, Hidalgo, México. Correo electrónico: mfelix@uaeh.edu.mx

Nota de los autores: Agradecemos los comentarios de dos compañeras, y sobre todo los de los evaluadores, quienes con sus observaciones enriquecieron el documento. Si bien tratamos de cubrir cada una de las sugerencias, las omisiones que aún pudieran encontrarse son responsabilidad nuestra. 


\begin{abstract}
This article analyzes the migration of the indigenous population within internal migration processes. The aim is to characterize the sociodemographic profile of these migrants, identify the predominant migratory patterns and determine the changes that the country's states have undergone as places of attraction and expulsion. The sources of information used are the microdata from the Population and Housing Censuses, 1990, 2000, 2010 and the Intercensal Survey 2015. We found that, for the case of the indigenous population, the predominant migratory pattern remains ruralurban and that the demographic profile of migrants is mostly males of reproductive age. Likewise, the states of Quintana Roo, Nuevo León, Sinaloa, Baja California and the State of Mexico have been consolidated as the states with the greatest attraction for indigenous migrants during the second decade of the millennium.
\end{abstract}

Keywords: Mexico; indigenous population; internal migration.

\title{
Introducción
}

Durante el siglo XX el incremento de la migración interna en México estuvo relacionado principalmente con los procesos de urbanización e industrialización del país, donde uno de los modelos económicos predominantes era el de industrialización por sustitución de importaciones (ISI). Para algunos estudiosos de la migración interna (Chávez, 1999; Partida, 2000a), el ISI explicaba en gran parte el patrón migratorio rural-urbano y el hecho de que la población se dirigiera principalmente a las nacientes ciudades. No obstante, se ha documentado que, ante el cambio de modelo económico y el contexto global de la economía mundial, la migración interna se ha transformado en su nivel y en la dirección de los flujos. Entre los factores que han incidido en la modificación de la movilidad territorial, Partida (2000a) destaca la creciente localización de las actividades industriales en ciudades intermedias, la conversión paulatina del sector manufacturero en establecimientos maquiladores, y la pérdida del dinamismo en el campo desde hace más de treinta años, donde sólo el sector empresarial de la agricultura del nordeste y noroeste fue el más beneficiado.

Entre las variaciones de la migración interna destaca su diversificación y su complejidad. En relación con la primera, se ha señalado que junto a los tradicionales y permanentes esquemas de migración campo a campo y campo a gran ciudad, se encuentra el traslado del campo a ciudades medias, ciudades medias a grandes ciudades, grandes ciudades a ciudades medias, y ciudades pequeñas, medias o grandes a ciudades fronterizas con el objeto de alcanzar ciertas zonas de trabajo localizadas en Estados Unidos (incluido Alaska) o Canadá (Chávez, 2009). En ese mismo registro, Sobrino (2013) 
denota procesos de continuidad caracterizados por una gradual disminución de la tasa de migración reciente, la consolidación del flujo urbano-urbano como predominante, una mayor cantidad de entidades federativas con saldo neto migratorio positivo, y la posición de la Ciudad de México y del Estado de México como puntos de origen y destino de los mayores montos de emigración e inmigración. En contraste, los procesos de cambio se documentan por la disminución absoluta en el flujo de migración reciente, la mayor desaceleración de la migración femenina, el aumento en la edad promedio del migrante, y la pérdida de atracción de algunas entidades como destino de la migración.

En relación con la complejidad, Cárdenas (2014) enfatiza entre otros fenómenos la intensidad y la modificación del patrón migratorio, pues los destinos finales de esta migración ya no son solamente la Ciudad de México, Guadalajara y Monterrey, sino que el abanico de urbes se ha ampliado con el aumento en el volumen de la migración indígena a partir de 1990 por la inclusión de mujeres y niños, además de la migración de los habitantes de las grandes ciudades. Respecto a estas transformaciones, pareciera confirmarse lo que Pérez y Santos (2013) denominan un nuevo mapa migratorio compuesto por tres procesos: el incremento de la movilidad interurbana (entre zonas metropolitanas y ciudades), la caída de la movilidad ruralurbana, y el papel de la Zona Metropolitana de la Ciudad de México. Para estos autores, los movimientos de población no únicamente han cambiado en términos de intensidad, sino principalmente de dirección. Aunque los desplazamientos rural-urbanos siguen siendo parte de la vida cotidiana, los movimientos entre ciudades se han convertido en los más importantes en términos cuantitativos. "A la par que se fortalece un nuevo patrón urbanoregional guiado por la transformación de la base económica regional, la movilidad tenderá a la desconcentración". De esta forma, ciudades emergentes consolidarán su papel como principales receptoras de la población, y se espera que la Zona Metropolitana de la Ciudad de México estabilice su balance neto migratorio (Pérez y Santos, 2013, pp. 82-83).

Dentro de este panorama general de la migración interna, en este documento nos proponemos caracterizar los flujos correspondientes a la población indígena. La migración de esta población tiene larga data, pues según Rubio et al. (2000) se tienen registros de los puntos de origen y de destino desde el siglo XIX; sin embargo, el despegue de las investigaciones sobre migración indígena se dio a partir de los setenta, con el trabajo pionero de Lourdes Arizpe sobre las indígenas mazahuas en la Ciudad de México (Durin, 2006; Vázquez y Prieto, 2012). En los últimos años, sobre todo a partir de los noventa, algunos estudiosos de la migración indígena se han centrado en el 
flujo que se dirige hacia las ciudades. Para Durin (2008, p. 26), fue en esa década cuando "salieron definitivamente a la luz los indígenas en las ciudades", tanto en México como en Latinoamérica. Por tanto, la cantidad de estudios dedicados a los indígenas residentes en las urbes aumentó de manera considerable. Desde su perspectiva, esto se debió a un contexto de politización de las fronteras étnicas y a la emergencia de los indígenas como actores políticos. De acuerdo con Cárdenas (2014), son tres los tipos de ciudades adonde se dirige la población indígena: industriales, agroindustriales y turísticas de sol y playa. Asimismo, señala que la razón de esta migración a las ciudades ya no es el proceso de industrialización, sino la globalización económica, pues el arribo a una urbe, con diferente vocación económica, no garantiza conseguir mejores oportunidades de vida; por ello algunos migrantes continúan su peregrinaje, ya sea de ciudad en ciudad, o de campo agrícola a campo agrícola, para finalmente internarse en Estados Unidos.

Por otra parte, también hemos detectado estudios que dan cuenta de la diversificación de la migración indígena. Entre estas investigaciones destaca la de Rubio et al. (2000, pp. 291-292), la cual evidencia que, a principios del milenio, el mapa de la distribución étnica nacional no sólo comprendía los asentamientos indígenas tradicionales, sino grandes cantidades de ciudades del país, zonas de fronteras internacionales y villas, y ciudades periféricas con importancia exclusivamente municipal o microrregional. Asimismo, reconocen que la Zona Metropolitana de la Ciudad de México ha disminuido su fuerza de atracción para los indígenas, ya que otras ciudades han adquirido importancia. Para Rubio et al. (2000), estos cambios se deben a la reorientación de las corrientes migratorias promovidas por la aparición o consolidación de zonas de desarrollo, que generan demanda de mano de obra en la agroindustria, los servicios y las zonas industriales, donde los indígenas se emplean en labores de baja calificación. Otro estudio similar es el de Partida (2000b), quien señala que, entre 1985 y 1990, las entidades de mayor atracción para los migrantes indígenas no sólo eran el Estado de México y la Ciudad de México, sino se sumaba Quintana Roo, que pasaba a ocupar el tercer sitio. Además, muestra que la mayoría de los migrantes provenían de áreas rurales con alta marginación y atraso; por tanto, la migración de la población indígena era consecuencia de la pobreza extrema y de las precarias condiciones de vida en las que se encontraban sus comunidades. Finalmente, Granados (2005) también indica la emergencia de nuevos polos de atracción de la migración indígena en el noroeste y suroeste del país, sobre todo en los estados de Sinaloa y Quintana Roo. Para este autor, estos nuevos sitios de atracción generaron su propio mercado de abastecimiento de mano de obra indígena y no compitieron con la Ciudad de México. 
Si bien Durin (2008) reconoce un creciente interés por el estudio de los indígenas en las ciudades, añade que sólo parte de ellos son visibles, y la mayoría aún escapan a las instituciones de gobierno y al escrutinio académico. En relación con ello, coincidimos en que son sólo ciertos grupos de población indígena quienes se han estudiado e identificado históricamente por su traslado a las grandes ciudades (Valencia, 2000), a las zonas agrícolas del noroeste del país (Velasco, 2011; Granados, 2009) o a las grandes fincas del sureste (Rubio et al., 2000). Desde nuestra perspectiva, la población indígena es tan diversa que resulta complejo encasillarla en un sólo patrón migratorio interno, así como en una sola perspectiva metodológica. Sin embargo, es necesario contar con información estadística reciente que dé cuenta de la migración interna de esta población en el ámbito nacional. En relación con dicha cuantificación, hemos detectado sólo dos estudios: el de Rubio et al. (2000) y el de Partida (2000b), quienes realizaron sus investigaciones con datos del Censo de 1990 y del Conteo de Población de 1995. No obstante, falta por indagar los cambios que ha tenido cuantitativamente esta migración en los últimos años. Conscientes de que una aproximación más acabada del panorama general deberá acoplar estudios estadísticos con los de carácter cualitativo, el objetivo central de este documento es caracterizar la migración interestatal de la población indígena entre 1990-2015, enfatizando, entre otras cosas, su perfil sociodemográfico, el patrón migratorio predominante, y los cambios que han tenido los estados del país como lugares de expulsión o atracción. A partir de ello, tratamos de contribuir a la "visibilidad estadística" de esta población frente a dichas modificaciones en los procesos migratorios internos.

La hipótesis que planteamos en este documento es que la migración de los indígenas se ha diversificado: la Zona Metropolitana de la Ciudad de México ha perdido atracción, y se han consolidado otros sitios, como la zona costera de Quintana Roo, las ciudades de Monterrey, Guadalajara y Tijuana, y los municipios agrícolas de Culiacán, Navolato y Elota (en Sinaloa). No obstante, el patrón migratorio predominante sigue siendo rural-urbano, y el perfil de los migrantes consiste en su mayoría en varones situados en las edades más productivas. Asimismo, las entidades de emigración ya no son sólo aquellas que históricamente han albergado los mayores volúmenes de población indígena en su territorio, sino que otras áreas, como la Ciudad de México, se han vuelto expulsoras de dicha población.

A partir de lo anterior, hemos dividido el texto en tres apartados. En el primero, detallamos la forma en que se identifica a los indígenas en los censos, escogiendo como nuestro universo de estudio a los hablantes de lengua indígena (HLI). Asimismo, reflexionamos sobre la manera en que se 
capta la migración en esta misma fuente, y nos acercamos a esta movilidad a partir de la pregunta sobre residencia en los cinco años previos a la fecha censal. En el segundo apartado abordamos algunas de las principales características sociodemográficas (constitución de la migración por sexo y edad) de la migración de los HLI en los años recientes, así como de los patrones migratorios predominantes. Finalmente, en el tercer apartado nos centramos en las nuevas dinámicas de las entidades federativas como zonas de atracción y expulsión de la población indígena.

\section{Aproximación a la población indígena y la migración interna}

En la cuantificación de los indígenas de México, el único indicador que ha sido utilizado de manera constante desde 1895 es el lingüístico, aunque en el Censo de 1921 se indagó la pertenencia a una raza (blanca, mestiza, india), y en 1940 y 1950 se incluyeron criterios de vestido autóctono, calzado (uso de huaraches) y alimentación con base en el maíz (Valdés, 2003; Serrano, 2005). El empleo del criterio lingüístico constituye una aproximación práctica para identificar a la población indígena; parte del supuesto de que la preservación de la lengua constituye el rasgo objetivo de mayor representación ante otros elementos, como las costumbres, los valores y las prácticas cotidianas que pueden identificar a los grupos étnicos. Para Corona y Serrano (2010), la aplicación del criterio lingüístico en los censos considera a la población total residente en el país, estado o municipio, según sea el caso. De dicha población se selecciona solamente a residentes de cinco años o más de edad, apartando del grupo a las personas de cero a cuatro años y a las que no especificaron su edad. Posteriormente, a la población de cinco años o más se le pregunta si hablan alguna lengua indígena, y en caso de una respuesta afirmativa, se indaga su condición de hablante de español y sobre la lengua indígena que practican; cabe destacar que en el Censo de 2010 el rango de edad fue mayor de tres años y en el 2015 no se consideró ningún criterio etario.

De acuerdo con Serrano (2005, p. 4), en la década de 1990 las cuestiones sobre la población indígena en México dieron un giro radical a partir de dos situaciones concretas. Por un lado, la "sensibilización" de los responsables de los sistemas nacionales de información respecto a la importancia de contar con datos de calidad permitió que se revisaran los catálogos de lenguas existentes, así como los procesos relativos al diseño de las preguntas censales y del operativo de campo en general. Por otro lado, tuvo lugar una reconsideración, por parte de los estudiosos de las ciencias sociales y en particular de los antropólogos, sobre la importancia de reconocer la especificidad de 
los fenómenos culturales y étnicos como factores determinantes de las condiciones de vida, la dinámica de la población y el desarrollo entre los grupos sociales, los cuales no están únicamente determinados por factores económicos.

Desde nuestro punto de vista, este contexto que señala Serrano (2005), más las reformas constitucionales en materia indígena y la existencia de un movimiento indígena fortalecido por el Ejército Zapatista de Liberación Nacional (EZLN), fueron factores que confluyeron para que en el Cuestionario Ampliado del Censo de 2000 se incluyera una pregunta relacionada con la pertenencia étnica (a cada persona mayor de cinco años se le preguntó si era náhuatl, maya, zapoteco, mixteco o de otro grupo étnico). Esta pregunta relativa a la autoadscripción se volvió a incluir en el Cuestionario Ampliado del Censo de 2010 y en la Encuesta Intercensal de 2015 (a las personas se les preguntó que si de acuerdo con su cultura se consideraban indígenas). Lo anterior muestra cómo el Instituto Nacional de Estadística y Geografía (INEGI) de México ha incorporado en los dos últimos censos y en la Encuesta Intercensal otros criterios, además del lingüístico, para cuantificar a dicha población. Instituciones como la Comisión Nacional para el Desarrollo de los Pueblos Indígenas (CDI) y estudiosos del tema, han realizado investigaciones empleando estas preguntas de pertenencia (Serrano, 2005; Fernández, 2011). Sin embargo, en este documento nos acercamos a la migración indígena utilizando solamente el criterio lingüístico en la cuantificación de dicha población, por la consistencia que ha tenido esta pregunta en los censos y en la Encuesta Intercensal. En un estudio realizado por Vázquez y Quezada (2015), los autores encontraron que la población mayor de cinco años que se declaró como indígena en el año 2000 ascendió a 5.3 millones, y en 2010 a 15.1 millones. Para estos autores tal incremento se debió al cambio de fraseo en la pregunta, al referir la condición étnica a la "cultura"; en 2010 ésta fue más permisiva para que la población se autoadscribiera como indígena y se sobreestimó su volumen. Asimismo, la población autoadscrita en el 2010 tuvo características sociodemográficas menos cercanas a las de los hablantes de lenguas indígenas: residían en localidades urbanas, tenían más escolaridad y mayor proporción de migrantes absolutos. Por otra parte, en 2015, de acuerdo con la Encuesta Intercensal, 23.5 millones de personas mayores de cinco años se declararon como autoadscritos; es decir, entre 2010 y 2015 hubo un incremento de 8.4 millones de indígenas por autoadscripción. De esta forma, el porcentaje de los autoadscritos en 2000, 2010 y 2015 ha sido de 6.1, 14.9 y $21.5 \%$, respectivamente.

En relación con los hablantes de lengua indígena (HLI), observamos que, si bien siguen creciendo de manera absoluta, están disminuyendo en 
términos relativos: mientras en 1930 el 16\% de la población mexicana hablaba una de esas lenguas, en 2015 sólo $6.5 \%$ presentaba esta característica. Por otra parte, la población HLI en México se ha concentrado en algunas entidades federativas, siendo las del centro y las del sur del país las que agrupan la mayor parte de tal población. Las dos entidades que sobresalen por su volumen de HLI son Chiapas y Oaxaca; ambas aglutinan un tercio de la población indígena del país (véase el Cuadro 1). Aunque hay que resaltar que en el último periodo de referencia, Chiapas se consolidó como la entidad con el mayor número de hablantes de lengua indígena, desplazando a Oaxaca. En tanto, los estados fronterizos y del noroeste han tenido poca presencia de esta población. Aunque es evidente que en algunos estados el tamaño de dicha población ha aumentado debido a la migración. Por ejemplo, entre 1990 a 2015 en Nuevo León la población indígena se incrementó más de diez veces, en Aguascalientes cuatro veces, en Zacatecas tres veces, en Baja California Sur casi tres veces, y en Colima y Tamaulipas casi al doble. En Baja California, Nayarit y Jalisco también se ha incrementado tal población, pero aún es muy pequeña y porcentualmente marginal (véase el Cuadro 1).

En lo referente a las principales lenguas indígenas que se hablaban en México en el año 2015 figuraban como las más relevantes, en orden de importancia: náhuatl, maya, tseltal, mixteco, tsotsil, zapoteco, otomí, totonaco, ch'ol, mazateco, huasteco, mazahua, chinanteco, tarasco, mixe y tlapaneco. Asimismo, en esta encuesta observamos que alrededor de 54 lenguas no tienen ningún peso relativo e incluso en algunas de ellas el número de hablantes es mínimo, por lo que es posible que éstas se pierdan en los próximos años.

En México, en los censos existen dos maneras para medir y cuantificar la migración. La primera es por la pregunta lugar de nacimiento, donde se cuestiona al entrevistado en qué entidad federativa nació. Las cifras obtenidas a partir de tal interrogante permiten observar los desplazamientos de las personas; sin embargo, al no contar con la fecha del cambio de residencia, se desconoce si el individuo se movió recientemente o desde hace mucho tiempo. Los datos tampoco permiten calcular algunos indicadores como la tasa de migración, pero son útiles para conocer la acumulación de migrantes en un espacio geográfico en el tiempo. La segunda manera es por la pregunta lugar de residencia en una fecha fija anterior, incorporada desde el Censo de 1990, que pretende dar a conocer el número de personas que se movieron entre las entidades federativas en México en una fecha fija, regularmente cinco años antes de la fecha censal. Con los resultados de esta pregunta se pueden hacer cálculos de tasas, pero al reflejar los movimientos recientes de personas, se pueden conocer los nuevos lugares 
de atracción y expulsión de la población en fechas cercanas a cada censo. Según Rangel Rigotti (2009, p. 227), una contribución importante de tal información es que:

La fecha fija permite el cálculo directo del saldo migratorio entre pares de unidades espaciales y muestra el número de inmigrantes y de emigrantes, según zonas de origen y destino. Estas cualidades ayudan a explicar por qué muchos autores coinciden en que, ante la necesidad de escoger sólo un tipo de información sobre migración interna, la pregunta sobre la fecha fija es la más indicada.

Además, considerando el criterio de lugar de residencia, en México se tiene una serie histórica de cifras de los movimientos migratorios en los siguientes quinquenios: 1985 a 1990, 1995 a 2000, 2005 a 2010 y 2010 a 2015, que muestran los cambios en las entidades receptoras o expulsoras de población.

La identificación de la población indígena que se mueve dentro del país también presenta sus complejidades. Al respecto, hay que tomar en cuenta que la mayor parte de los grupos indígenas residen en espacios rurales y buena parte de ellos todavía se emplean en el sector agropecuario. Esto implica que, si se quiere enumerar de la mejor manera posible los desplazamientos de los HLI, la fecha para captar los procesos migratorios debe estar acorde con los periodos de cosecha de los cultivos que se producen con mayor intensidad en el país. Entre ellos podemos mencionar el de la zafra, así como una serie de productos agrícolas que se localizan principalmente en el noroeste del país. Por ejemplo, un producto como el jitomate requiere un uso intensivo de mano de obra tanto para la siembra como para su cosecha, y concentra su producción especialmente en los meses de enero, febrero y marzo. En tanto, su nivel mínimo lo tiene durante el verano, en los meses de junio y julio. Por ello, si se desea registrar el mayor número de migraciones rurales en México (donde consideramos que una parte importante de estos movimientos son de origen indígena), se debe llevar a cabo el levantamiento de la información sociodemográfica en los primeros meses del año y no a mediados, como se hizo en el Censo de 2010 (se tomó como fecha censal el 12 de junio), al contrario de lo que había ocurrido en los censos de 1990 y 2000 (con fechas censales de 12 de marzo y 14 de febrero, respectivamente); por su parte, la Encuesta Intercensal 2015 estableció como fecha el 15 de marzo 2015. Es por ello que consideramos que el Censo de Población 2010 subestimó los movimientos de migración indígena, sobre todo a los estados de mayor importancia agrícola, como los del noroeste de México. 


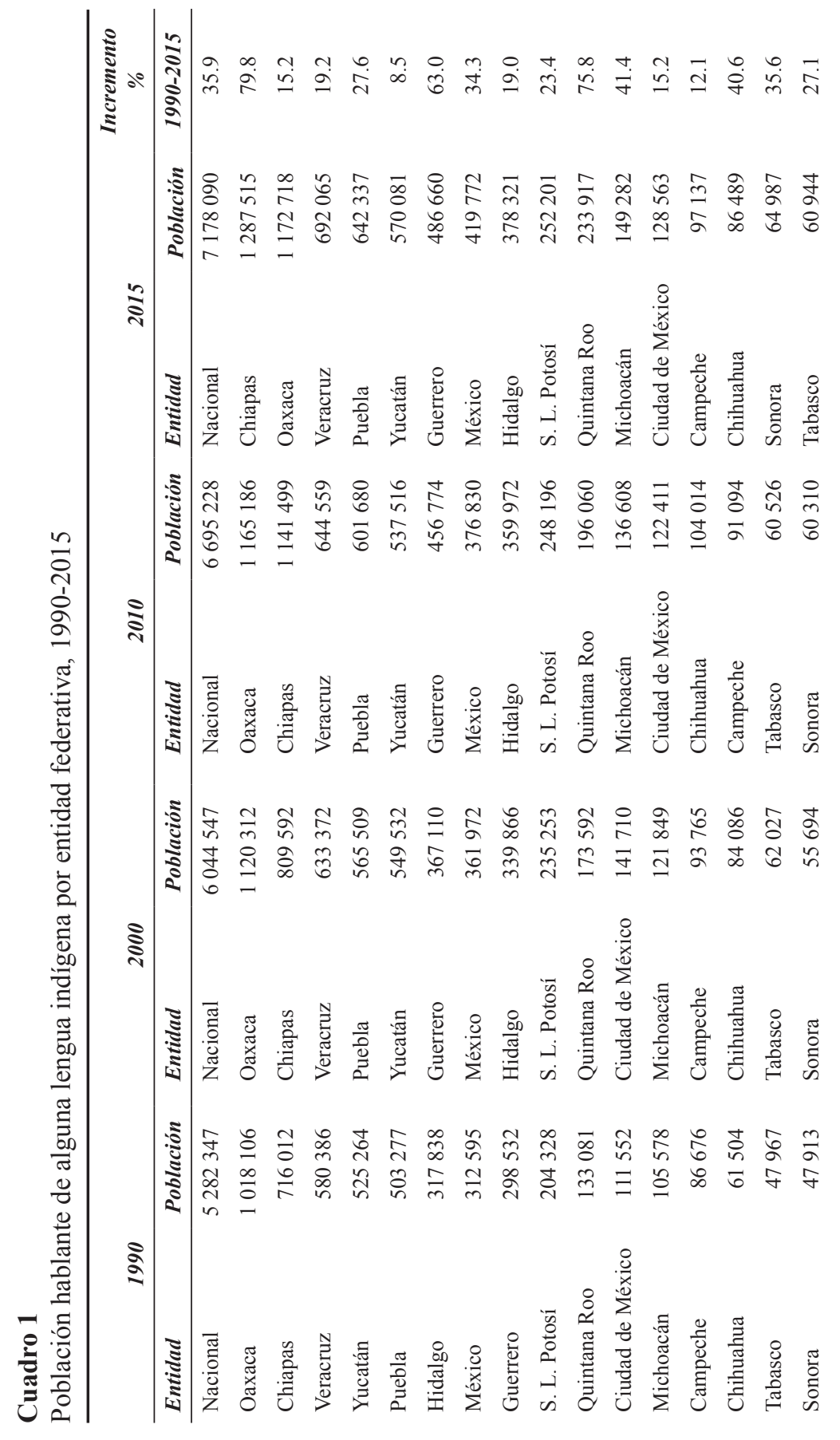




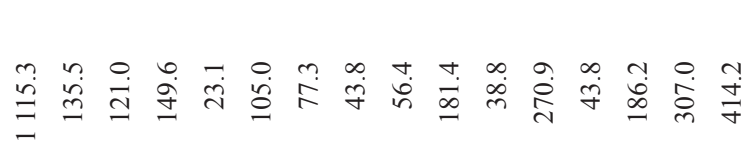

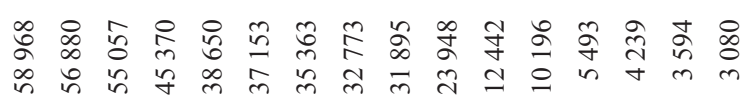

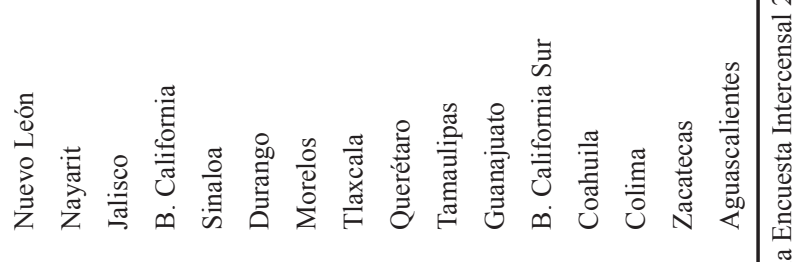

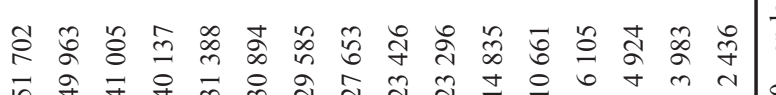

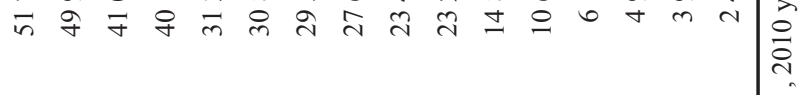

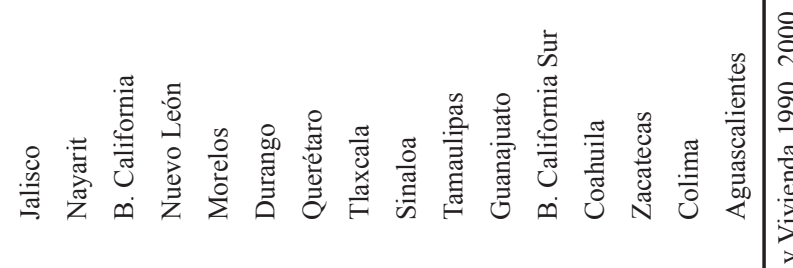

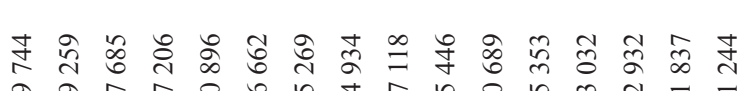

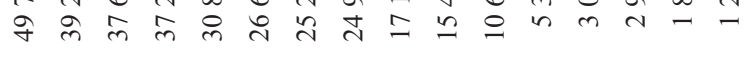

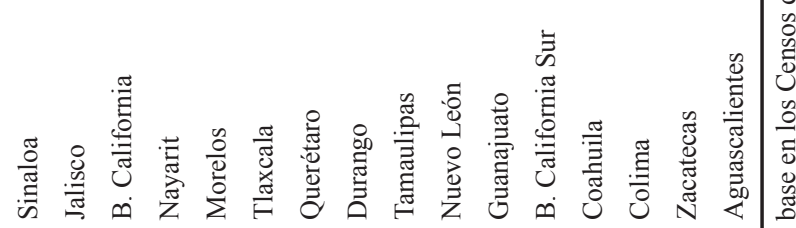

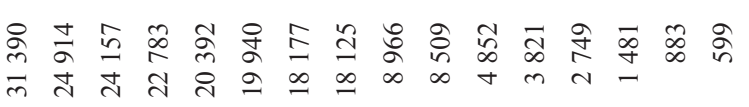

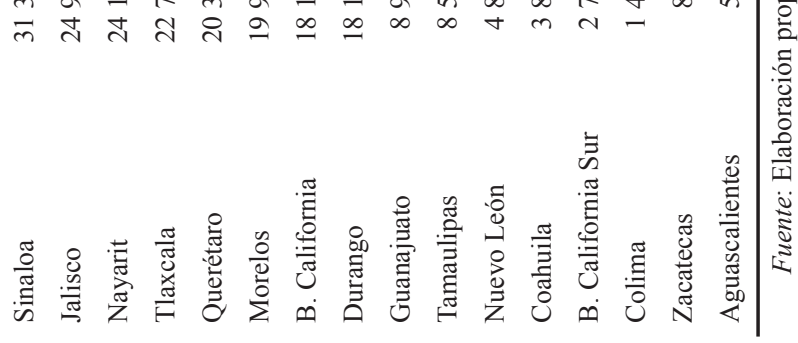




\section{Características sociodemográficas de los migrantes indígenas}

La Encuesta Intercensal 2015 registró que 3.2 millones de personas de 5 o más años de edad vivían en marzo de 2010 en una entidad distinta a la de su residencia en marzo de 2015. De ellas, 5.7\% eran HLI, es decir, más de 183 mil personas HLI cambiaron su residencia a una entidad diferente. Esta cifra representó a 2.6 \% de la población HLI mayor de 5 años en México, mientras que el porcentaje de los no hablantes de lengua indígena (NHLI en lo sucesivo) fue levemente mayor (3.0\%). Es preciso enfatizar que la migración interna en el país muestra una tendencia descendente en años recientes, pues mientras en el periodo de 1995 a 2000 el porcentaje de personas mayores de 5 años que se movieron representó $4.5 \%$, entre 2000 a 2005 fue de $3.3 \%$, y para el quinquenio 2010-2015 se ubicó en 3.0\%. Esta caída de la migración interna también afectó a la población indígena, ya que en los mismos periodos de referencia los porcentajes fueron 3.6, 3.3 y $2.6 \%$ respectivamente.

La migración indígena en el año 2015 está constituida principalmente por hombres, más que por mujeres, y el índice de masculinidad de la población indígena migrante es de 112 hombres por cada 100 mujeres. Este índice es lo contrario para los NHLI, ya que para este grupo el flujo migratorio está constituido mayoritariamente por mujeres: algo más de 98 hombres por cada 100 mujeres. Respecto a la edad (véase la Gráfica 1), este flujo de migración indígena se constituye por personas jóvenes que están en el apogeo de sus capacidades físicas; se trata de un patrón de migración laboral donde la distribución por edades muestra una migración tradicional. Esto quiere decir que la curva etaria presenta una concentración en las edades productivas, con una leve participación de las edades infantiles y avanzadas. En cambio, la estructura de edad de los NHLI está más asociada a la migración familiar donde los grupos infantiles y productivos tienen una destacada participación porcentual, mientras que es menor la participación en las edades avanzadas. De esta forma, la migración de los NHLI presenta un patrón más "moderno" relacionado con una migración urbana-urbana. En ese sentido, la motivación para migrar no sólo está relacionada con la búsqueda de empleo o mejores trabajos, sino también con el deseo de la reunificación familiar o el anhelo de mejores ambientes para vivir.

Esta migración de los HLI tiende a moverse más hacia los espacios rurales que la migración de los NHLI, ya que mientras $26.1 \%$ de los migrantes HLI se dirigieron hacia localidades menores de 2500 habitantes en 2015, para los NHLI esta cifra fue de $14.1 \%$. En cambio, la migración de los NHLI se caracteriza más por desplazarse hacia localidades mayores de 100 mil habitantes; los datos de la encuesta indican que más de la mitad de la población 


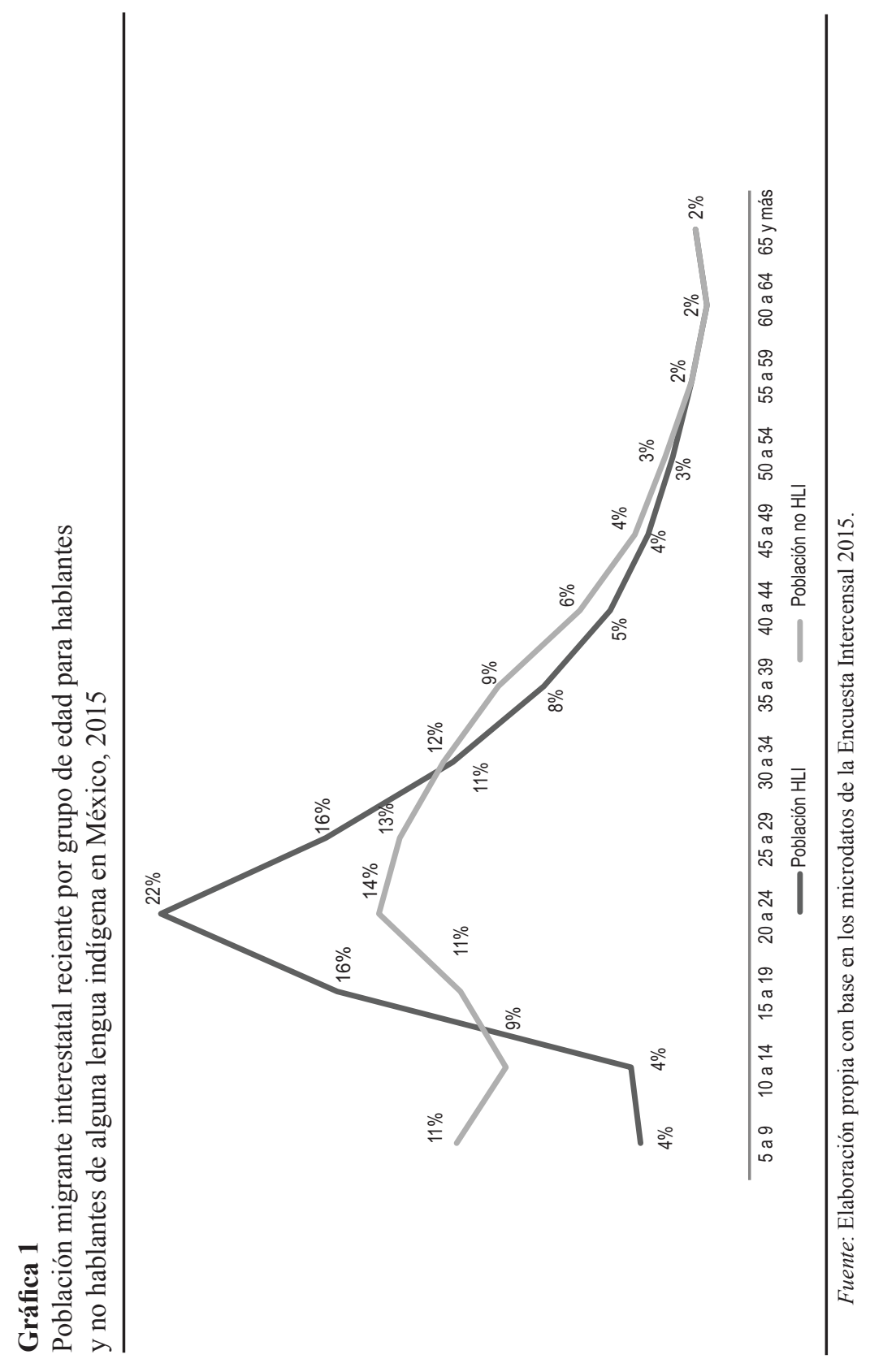


NHLI (56.8\%) se movió hacia esas localidades urbanas, en tanto para los HLI representó $46.6 \%$. Este comportamiento se explicaría por factores como la concentración de la población indígena en localidades rurales, y porque esta movilidad de migrantes indígenas hacia este tipo de localidades también podría ser una migración de retorno, pues es conocido que estos migrantes regresan a su lugar de origen después de pasar un tiempo laborando en otras regiones del país; tal es el caso de quienes se dedican al jornalerismo. Según Canabal y Olivares (2016), el jornalerismo se ha convertido en una forma de vida para grandes sectores campesinos de autosubsistencia y es la única posibilidad de que obtengan un ingreso antes de volver a sus comunidades para sembrar y participar en sus actividades y cargos. Por otra parte, el hecho de que casi la mitad del flujo migratorio indígena se dirige hacia las ciudades de más 100 mil habitantes, nos indica que esta población también ha encontrado facilidades de asentamiento en estas urbes.

Finalmente, a partir de los datos de la Encuesta Intercensal la migración indígena presenta dos patrones migratorios predominantes: rural-urbano y rural-rural. De acuerdo con la información de esta misma fuente, las personas de origen nahua son las que se desplazaron con mayor intensidad ya que este grupo concentró $31 \%$ de los movimientos migratorios indígenas; le siguen en orden de importancia los mixtecos $(9.7 \%)$, los mayas (7.4\%), los zapote$\cos (6.9 \%)$ y los mazatecos $(5.8 \%)$. Estos cinco grupos lingüísticos fueron los que reunieron más del $60 \%$ de la migración indígena interestatal. En el siguiente apartado nos centramos en mostrar las transformaciones de la migración interestatal de los HLI, y destacamos las principales entidades de atracción y de expulsión.

\section{Las entidades de atracción de HLI}

El análisis del saldo neto migratorio (diferencia entre inmigrantes y emigrantes) de los HLI en 2015 nos muestra cuáles son las entidades que ganaron más población indígena y aquellas donde sucedió lo contrario. A partir de este criterio, en los estados donde hubo mayor ingreso de población indígena observamos lo siguiente: a) la permanencia de Quintana Roo como la principal entidad de atracción de migrantes indígenas en el país; $b$ ) la consolidación de Nuevo León como entidad receptora de migrantes indígenas; c) el fortalecimiento del Estado de México como entidad que también recibe migrantes indígenas; d) el ascenso de Sinaloa y Baja California como los estados del noroeste del país que más acogieron migrantes indígenas, y e) la emergencia del trabajo agrícola de indígenas en el sureste de Jalisco (véase 
los Cuadros A1, A2, A3 y A4 en el Anexo). De manera general describimos los perfiles de estos migrantes en cada una de estas entidades.

\section{Quintana Roo}

Quintana Roo es un estado de atracción de migrantes en la región sureste del país, tanto de población no indígena como indígena, desde los años setenta, cuando se detonó la actividad turística en su franja costera con la creación del proyecto de Cancún. ${ }^{1}$ La expansión económica de esta zona turística se combinó con la crisis de la producción henequenera (por el desuso en que ha caído esta fibra debido al aumento en el empleo de las fibras sintéticas) en la Península de Yucatán. Esto provocó entre otras cosas que fuertes contingentes de población indígena de la zona maya del estado de Yucatán se trasladaran al vecino estado de Quinta Roo. De esta forma, en Quintana Roo se combinó la atracción ejercida por un territorio despoblado con la expulsión de población yucateca de otras entidades (Rubio et al., 2000). Actualmente, el flujo más cuantioso que se genera en la Península de Yucatán procede de estas dos entidades federativas, puesto que la población indígena en 2015 representa $71.2 \%$ de los inmigrantes en Quintana Roo y 90.9\% de la emigración de Yucatán. La gran variedad de servicios turísticos que se ofrecen en Cancún ha provocado que $63 \%$ de los nuevos inmigrantes étnicos laboren en el sector servicios, aunque todavía 32\% de los inmigrantes se encuentran incorporados en el sector industrial, principalmente en la construcción. Asimismo, el flujo migratorio está constituido principalmente por población masculina, ya que $60 \%$ de los migrantes indígenas recientes son hombres.

En el sur de Quintana Roo se presentan otras dinámicas migratorias debido a la atracción anual que ejerce el periodo de zafra (entre noviembre y junio) del ingenio azucarero de San Rafael de Pucté, en el municipio de Othón P. Blanco, jurisdicción limítrofe con el vecino país de Belice. Se trata de migraciones temporales agrícolas por la demanda principal de cortadores de caña, quienes llegan en grupos o en familia, como en el caso de los jornaleros indígenas. García (2013) ha documentado que desde principios de los años ochenta del siglo XX, este enclave ha atraído mano de obra agrícola de diversos estados mexicanos, siendo la población indígena de

\footnotetext{
${ }^{1}$ Se estima que de 1970 a la fecha se han construido en la entidad más de 2800 cuartos de hospedaje, principalmente en Cancún; esta ciudad actualmente cuenta con toda una infraestructura hotelera de primer nivel ( $76 \%$ son de cuatro estrellas), servicios turísticos como discotecas, restaurantes, plazas comerciales, etc., para atender los requerimientos del turismo nacional e internacional (Valencia, 2000, p. 86).
} 
Veracruz y Puebla (nahuas), Oaxaca (zapotecos) y Chiapas (tseltales, tsoltsiles y choles), los principales proveedores de esta fuerza laboral. En ese contexto y dentro de las dinámicas transfronterizas, la autora señala que existen migraciones de trabajadores internacionales, como los cortadores de caña originarios de Guatemala (de raíz mam, principalmente) y Belice. Los primeros son producto de su paso por esta entidad en el proceso de refugio y ahora están nacionalizados. En relación con los trabajadores temporales de origen mam, entre otros grupos de Guatemala, Santos y García (2015) documentaron su empleo en las zafras del ingenio de La Joya, Campeche, en donde aportan cerca del $50 \%$ de la mano de obra, pero se trata de los guatemaltecos que se asentaron en esa entidad y que ya están nacionalizados. ${ }^{2}$

\section{Nuevo León}

A principios del milenio, Nuevo León se constituyó como una de las principales entidades de atracción de migrantes indígenas del país debido al dinamismo económico de su principal ciudad, que es Monterrey. Ésta se ha vuelto muy atractiva para los migrantes indígenas por la abundancia de empleo en el sector informal, ya que a pesar de la carencia de seguridad social se ofrecen sueldos más altos que en sus lugares de origen (Durin, 2003). En 2015 residían en Nuevo León más de 58 mil HLI, de éstos, 85\% habitaba en alguno de los once municipios que conforman la Zona Metropolitana de Monterrey.

El número de migrantes HLI captados en la Encuesta Intercensal de 2015 en Nuevo León fue de cerca de 15 mil personas; de ellas, 55\% son del sexo masculino. Según Durin (2006), la migración indígena hacia Monterrey desde 1970 siguió un patrón migratorio tradicional, pues los migrantes tienen un perfil mayormente masculino, aunque a partir de 1990 aumentó el volumen de la migración indígena femenina, que actualmente constituye el $45 \%$ de esta migración. Se destaca que la población migrante es joven, ya que la mediana de edad fue de 23 años. Las entidades de donde provienen estos migrantes son: el vecino estado de San Luis Potosí (39.8\%), Veracruz (20.7\%) e Hidalgo (12.6\%); es decir, $72 \%$ de los migrantes vivían en esos estados en 2010. El 84\% de estos migrantes se concentraban en la Zona Metropolitana

\footnotetext{
${ }^{2}$ Por otra parte, en un amplio estudio en cuatro ingenios de la frontera sur, se registra la presencia de grupos indígenas de Guatemala que año tras año, desde hace por lo menos tres décadas, arriban a la región cañera del ingenio de Huixtla (Chiapas), tanto de grupos masculinos como familiares. Estos conjuntos laborales temporales han llegado a ser hasta de 500 cortadores (García y Décosse, 2014).
} 
de Monterrey, y la mayor parte de ellos llegaron a los municipios conurbados de esta metrópoli; al municipio de Monterrey sólo llegaron 27\% de los migrantes indígenas, el 57\% restante se estableció en los municipios conurbados de esta zona metropolitana, principalmente en Juárez, García, Santa Catalina y Escobedo.

Poco más de la mitad de los migrantes HLI refirieron hablar náhuatl (52.4\%); en segundo lugar se encontraban los hablantes de huasteco (23.4\%), y en tercer lugar, los hablantes de zapoteco (3.9\%). Asimismo, 76\% de estos migrantes trabajaban, de ellos $18.3 \%$ laboraban como empleados domésticos, $10 \%$ en el comercio al por menor, y $9 \%$ en la preparación de alimentos y bebidas. Finalmente, sólo un porcentaje mínimo de estos migrantes HLI se insertó en actividades agropecuarias.

\section{Sinaloa}

Sinaloa es el estado del noroeste del país que en el periodo de referencia (2010-2015) atrajo más de once mil personas hablantes de alguna lengua indígena; sin embargo, llama la atención que durante el periodo de 2005 a 2010 perdió población indígena. Aunque este dato debe tomarse con cuidado ya que dicha entidad federativa cuenta con un importante sector agrícola, siendo la horticultura una actividad de gran dinamismo que se efectúa de enero a mayo, por lo que la migración de personas que trabajan en esas labores no fue captada en toda su intensidad, sobre todo en el periodo censal de 2010, que se levantó en el mes de junio. La agricultura condiciona el mercado laboral en Sinaloa, ya que las tareas agrícolas (sobre todo la siembra hortícola) ofertan un empleo que se caracteriza por su baja remuneración y precariedad, en gran medida temporal y ocupada principalmente por inmigrantes indígenas dedicados al jornalerismo. Lo anterior se demuestra con las cifras de la Encuesta Intercensal, ya que 87\% de los migrantes captados trabajaban en actividades agrícolas. Desde nuestra perspectiva esto explica por qué $65 \%$ de los migrantes HLI sinaloenses son del sexo masculino y muy jóvenes (cuentan con una mediana de edad de 23 años). Sus principales lenguas son náhuatl (44.1\%), zapoteco (10.1\%) y mixteco (12.3\%).

Al respecto, se ha demostrado que la población que arriba a Sinaloa trabaja sobre todo en el sector agropecuario y se asienta en localidades rurales; este patrón no ha cambiado ya que en 2015 más de la mitad de los migrantes (54\%) se establecieron en localidades menores de 2500 habitantes, y menos de $20 \%$ en localidades mayores de 100 mil habitantes. Finalmente, el flujo de personas HLI ha convertido a Sinaloa en una de las regio- 
nes primordiales de atracción de esta población principalmente originaria de Guerrero, Oaxaca y más recientemente, como lo demuestran los datos de la Encuesta Intercensal, de Veracruz. La incorporación de este último estado al flujo migratorio que se dirige a Sinaloa es relevante pues en 2015 se constituyó como la segunda entidad de expulsión de migrantes hacia Sinaloa, sólo superada por Guerrero. De esta forma, Guerrero, Veracruz y Oaxaca concentran las dos terceras partes del flujo migratorio hacia Sinaloa, donde la participación de cada una de ellas ronda en 30.2, 22.6 y 12.4\%, respectivamente. Estos migrantes indígenas se asientan principalmente en las localidades rurales de los municipios de Navolato, Culiacán y Elota. Por tanto, el patrón migratorio predominante en Sinaloa es rural-rural. Además, el hecho de que estos migrantes indígenas sean contratados en sus comunidades y trasladados hacia Sinaloa, y al término del levantamiento de la cosecha se les regresa a sus asentamientos, hace que ésta sea una migración pendular (Granados, 2005).

\section{Estado de México}

El Estado de México se consolidó como entidad receptora de migrantes indígenas en los últimos lustros, y una buena parte de éstos son originarios de la Ciudad de México. Según la Encuesta Intercensal de 2015, de los más de 25 mil hablantes de alguna lengua indígena que arribaron al Estado de México, 28\% residía en la Ciudad de México. Este hallazgo es relevante pues históricamente la capital del país ha sido un lugar de asentamiento para esta población que proviene de las entidades vecinas. Esta tendencia indica, entre otras cosas, que la población indígena se está asentando en los municipios periféricos de la Zona Metropolitana de la Ciudad de México (ZMCM). Desde 1990 ya se resaltaba el asentamiento de diversos grupos indígenas en los municipios periféricos de la ZMCM; Hiernaux (citado en Velasco, 2007), en un trabajo realizado en el Valle de Chalco, distinguía tres grupos como los más significativos entre los pobladores de origen indígena: mixtecos, mayas y purépechas.

De acuerdo con los datos de la Encuesta Intercensal 2015, las lenguas que predominan en estos migrantes del Estado de México son náhuatl (28\%), mixteco $(15.1 \%)$, mazateco $(9.9 \%)$ y totonaca $(6.5 \%)$. Como ya se anotó anteriormente, más de una cuarta parte de los migrantes provienen de la Ciudad de México, pero también de otras entidades como Oaxaca (21.4\%), Puebla (9.8\%), Hidalgo (6.1\%) y Veracruz (8.5\%). Estos migrantes se asientan en localidades de más de 100 mil habitantes $(63.5 \%$ de ellos se concen- 
tran en estas ciudades), y sólo una de cada diez lo hace en localidades rurales. La relación de hombres y mujeres de estos migrantes es casi idéntica, ya que $50.5 \%$ son del sexo masculino y $49.5 \%$ del femenino. Finalmente se observa una diversificación de las actividades laborales, pero sobresalen los migrantes que trabajan como empleados domésticos, en la preparación de alimentos y en el comercio al por menor.

\section{Baja California}

La migración de indígenas hacia Baja California se ha concentrado en Tijuana; según Velasco (2011), la situación de esta ciudad debe entenderse bajo el contexto de la migración internacional y por su condición transfronteriza. La autora ha documentado que esta migración hacia Tijuana comenzó desde los años cuarenta, pero se intensificó en los setenta y ochenta, cuando se generaron los primeros asentamientos de grupos mixtecos provenientes de Oaxaca. Los indígenas en esta ciudad fronteriza se han concentrado en actividades del comercio informal, sobre todo en la producción y venta de artesanías para los turistas extranjeros, especialmente estadounidenses. Según la Encuesta Intercensal 2015, más de siete mil migrantes HLI residentes en Baja California provenían de otra entidad federativa; de ellos, un tercio vivía en el municipio de Tijuana. Baja California también atrae población indígena que labora en la agricultura; esta actividad se genera principalmente en el Valle de San Quintín, en el municipio de Ensenada. En este valle la Encuesta Intercensal registró a 2313 migrantes HLI, lo que representa 33.6\% de los migrantes indígenas que llegaron a Baja California. De igual manera, el municipio de Mexicali concentró $28.8 \%$ de ese flujo de migrantes. Los migrantes indígenas se dispersan en las diversas localidades que existen en la entidad: $13 \%$ vive en localidades menores de 2500 habitantes, 43.1\% reside en localidades mayores de 100 mil habitantes, y una cuarta parte de ellos se asienta en ciudades pequeñas de 15 mil a 49999 habitantes. Estos datos muestran la diversificación geográfica que tienen los migrantes indígenas en Baja California.

En cuanto al grupo lingüístico de los migrantes, destacan los mixtecos (26.9\%), mixes $(15.9 \%)$, zapotecos $(12.0 \%)$, nahuas $(11 \%)$ y en menor grado los tseltales $(4.7 \%)$ y tsoltsiles $(5.6 \%)$; estas lenguas pertenecen a las comunidades indígenas de Oaxaca, Guerrero y Chiapas, de donde proceden 44, 11 y $8.7 \%$ de estos migrantes, respectivamente. Las personas del sexo masculino son mayoritarias en este flujo (55.8\%). Si bien el sector agrícola es la principal actividad económica donde se emplea los migrantes indígenas,

Estudios Demográficos y Urbanos, vol. 33, núm. 2 (98), 2018, pp. 327-363 ISSN 0186-7210; e-ISSN 2448-6515; doi: http://dx.doi.org/10.24201/edu.v33i2.1726 
también resaltan otros sectores como el manufacturero. Según la Encuesta Intercensal, $18.6 \%$ de los migrantes labora en este sector, donde $3.6 \%$ se emplea en el subsector de fabricación de equipo de computación, comunicación y mediación, y $2.3 \%$ en la fabricación de equipo de transporte y autopartes. En tanto 5.1\% labora en la preparación de alimentos y bebidas, y sólo $2.8 \%$ trabaja como empleado doméstico.

\section{Jalisco}

Desde la época virreinal, Guadalajara, ubicada en el estado de Jalisco, se ha consolidado como una ciudad receptora de migrantes indígenas, característica que continúa en la actualidad. De acuerdo con los datos censales de 2010, existen 20256 indígenas en la Zona Metropolitana de Guadalajara (ZMG), pertenecientes a los grupos purépechas, mixtecos, náhuatl, tseltales, huicholes y en su gran mayoría otomíes. Según el Programa Desarrollo Integral para la Familia (DIF) de Jalisco, los inmigrantes indígenas se concentraban principalmente en 30 colonias, de las cuales cinco están en Zapopan, seis en Guadalajara, una en Tonalá, y el resto en Tlaquepaque. La Encuesta Intercensal 2015 registró a 6763 personas migrantes HLI, de las que 62\% residía en los ocho municipios de la ZMG, siendo Zapopan (32.9\%) y Guadalajara $(10.2 \%)$ los que concentraban la mayor cantidad de estos inmigrantes. Tomatlán y Zopotiltic son municipios que no pertenecen a la ZMG, pero son importantes receptores de migrantes indígenas ya que recibieron 5.6 y $4.3 \%$ de migrantes, respectivamente. El hecho de que estos municipios rurales jaliscienses se constituyan como receptores de migrantes indígenas se debe a que en la última década se han suscitado transformaciones en las actividades agrícolas que demandan mano de obra indígena. Al respecto, Hernández (2014, p. 16) señala que con la expansión comercial del tequila se desencadenó una migración de jornaleros indígenas a los campos agaveros en la región productora de los Altos de Jalisco, que desde su punto de vista es "un fenómeno inédito". Esta especialización trajo consigo oportunidades laborales para otras personas, y por tanto abrió oferta para los jornaleros indígenas provenientes del sureste mexicano. El autor subraya que los jornaleros indígenas no desplazaron laboralmente a los pobladores de las regiones altas de Jalisco, quienes se quedaron con los trabajos mejor remunerados, con cierta especialización y sin mucho desgaste físico. Sin embargo, las masivas migraciones indígenas en el contexto de la especialización del mercado de trabajo, generaron nichos laborales para los jornaleros indígenas, asignándoles los trabajos con mayor exigencia y desgaste físico, y menor retribución. 
Este proceso que señala Hernández (2014), se refleja en la Encuesta Intercensal, donde se detectó que $12.8 \%$ de los migrantes recientes de origen étnico se emplea en actividades agrícolas; el resto trabaja en una heterogeneidad de empleos como la construcción (5.6\%), los servicios de preparación de alimentos (4.5\%) y como empleados domésticos (11.3\%). Entre los principales estados de donde provienen estos migrantes recientes destacan: Hidalgo (16.2\%), Michoacán (13.2\%), Guerrero (12.8), Veracruz (11\%) y Oaxaca (10.5\%). De esta manera, las lenguas que mayormente hablan tales migrantes son: náhuatl (40.5\%), mixteco (12.1\%) y purépecha $(11.9 \%)$. Asimismo, 55\% de los migrantes recientes son hombres, lo que muestra su preponderancia.

\section{Las entidades de expulsión de HLI}

En 1990, las entidades que más perdieron población HLI fueron: Oaxaca, Yucatán, Guerrero, Hidalgo, Puebla, Chiapas, San Luis Potosí y Michoacán. Para 2015 la posición de las entidades expulsoras había cambiado y presentaba este orden: Chiapas, Oaxaca, Guerrero, Veracruz, San Luis Potosí, Yucatán, Puebla, Ciudad de México e Hidalgo. A excepción de la Ciudad de México, estas entidades de emigración han sido el territorio histórico de los mayores asentamientos de población indígena en el país. En esta distribución llama la atención la situación de Chiapas y Veracruz: la primera figuraba en 1990 en la sexta posición, pero en 2015 pasó a ser la primera entidad expulsora de población indígena; la segunda presentaba en 1990 un saldo neto migratorio positivo y destacaba como entidad de atracción, sin embargo, en 2015 se volvió el cuarto estado expulsor. Por otra parte, Michoacán sigue siendo un estado con saldo neto negativo, pero ha ido perdiendo peso; lo mismo sucede con Hidalgo, en tanto la Ciudad de México se colocó dentro de los principales estados expulsores de población HLI en 2015. En lo que sigue damos cuenta de lo que ha sucedido en dichos estados expulsores, centrándonos sólo en aquellos que han sido territorio histórico de HLI.

\section{Chiapas}

En 2015 Chiapas aumentó en más del doble la pérdida de su población indígena respecto a los censos anteriores; el flujo de chiapanecos se orienta principalmente hacia Quintana Roo, Tabasco y Baja California, siendo estas tres entidades las que agrupan $61.8 \%$ de los emigrantes indígenas chiapane- 
cos. Villafuerte y García (2014, p. 17) señalan que las migraciones interestatales de los chiapanecos se perfilaron más claramente a partir de los setenta debido a tres factores: 1) conflictos agrarios por la permanencia de una estructura concentrada en grandes latifundios frente a una masa de campesinos sin tierra; 2) el descubrimiento de grandes yacimientos de petróleo y gas en el área norte de Chiapas y territorios de Tabasco, y 3) la construcción del megaproyecto turístico de Cancún en Quintana Roo. Para los autores, estos tres hechos generaron una fuerza de atracción para "miles de chiapanecos que se encontraban en el límite de subsistencia y que en una década y media aprendieron a desplazarse lejos de sus tierras". Aunado a lo anterior, se sumaron la crisis de los principales productos del campo, el levantamiento armado del Ejercito Zapatista de Liberación Nacional (EZLN) y los desastres causados por los huracanes Mitch en 1998 y Stan en 2005. Finalmente, Villafuerte y García (2014) también señalan un crecimiento de la emigración de chiapanecos a las entidades fronterizas del norte del país, e incluso a Estados Unidos.

Respecto a la situación migratoria de Chiapas, Martínez (2013, p. 53) también indica que hay que considerar las condiciones históricas de desigualdad en la entidad. Esto propició el establecimiento, reproducción y sobrevivencia de "regiones de pobreza lacerante asociadas a la población indígena asentada en la región llamada Altos, que en los primeros años del pasado siglo se constituyó en reserva de mano de obra". Para el autor, las grandes tendencias migratorias desarrolladas por la población chiapaneca son: a) una migración intraestatal de trabajo temporal asalariado en establecimientos agrícolas durante 1920 a 1970; b) el arrendamiento de tierras en áreas de gran concentración terrateniente de 1940 hasta finales de 1990; c) el intermitente trabajo asalariado y por cuenta propia en los centros urbanos iniciado en la década de 1970 y hasta la fecha; $d$ ) la migración regional y nacional, significativamente a la Ciudad de México y en menor medida a Tabasco, Veracruz y Estado de México, de 1970 y 1990, y e) la migración de mayor distancia en los años 2000 a 2005 con dirección a Quintana Roo (Cancún y Playa del Carmen) y Baja California (Tijuana).

\section{Oaxaca}

Oaxaca es el segundo estado expulsor de población indígena en el país. El flujo de migrantes indígenas oaxaqueños se direcciona principalmente al Estado de México, la Ciudad de México y Baja California; de hecho, más de cuatro de cada diez migrantes indígenas de esa entidad se dirigen hacia 
esas tres entidades. Una de las condiciones que hacen posible este proceso migratorio es que esta entidad es una de las más marginadas del país; ${ }^{3}$ asimismo, más de la mitad de su población vive en localidades rurales, y su economía se sustenta en las actividades agropecuarias. En este sector labora más de la mitad de la población económicamente activa del estado, y en las últimas décadas ha existido un deterioro en los ingresos de las personas que viven de dichas actividades. Además de estos factores, se pueden citar otros como los desastres naturales, la persecución religiosa y los problemas políticos (García, 2007, p. 85). Rubio et al. (2000) han identificado las siguientes etapas del proceso migratorio interestatal en Oaxaca: la primera es una migración golondrina (hacia la zafra cañera y cafetalera de Córdoba y Sotavento en Veracruz) que se consolidó entre 1900 a 1930, compuesta principalmente por zapotecos y mixtecos. La segunda se dio en 1942 con la construcción de la Carretera Panamericana, lo que posibilitó que la población se desplazara hacia entidades como la Ciudad de México, Puebla y Veracruz. La tercera se presentó a finales de los cincuenta y en los sesenta con destino hacia el noroeste del país, sobre todo hacia Culiacán, Sinaloa, para emplearse en la pizca de jitomate. Para 1970, a Sinaloa se sumaban Sonora y Baja California como destinos predilectos de la migración oaxaqueña indígena hacia el norte. Destaca en Baja California el Valle de San Quintín, como un lugar de asentamiento de indígenas oaxaqueños, aunque en este valle también confluyen otros grupos indígenas del país. A partir de datos del Censo de 1990, Rubio et al. (2000) afirmaban que la mayoría de los migrantes indígenas oaxaqueños eran de filiación mixteca. Con base en la Encuesta Intercensal de 2015 podemos señalar que esta tendencia ha cambiado pues el grupo nahua es el que más se desplazó en el periodo de 2010 a 2015; el grupo mixteco fue el segundo.

\section{Veracruz}

De acuerdo con los datos censales, Veracruz fue una entidad de atracción de población indígena hasta 1990, pero en las últimas tres referencias (2000, 2010 y 2015) figuró como estado expulsor de población. Uno de cada tres HLI veracruzanos emigra principalmente a la Ciudad de México, Nuevo León o Tamaulipas. La conversión de Veracruz en una región expulsora de mano de obra, según Velásquez (2013, p. 89), comenzó en la década de 1980,

${ }^{3}$ Según el Consejo Nacional de Población (Conapo, 2012), en 2010 fue la tercera entidad con muy alto grado de marginación en el país.

Estudios Demográficos y Urbanos, vol. 33, núm. 2 (98), 2018, pp. 327-363 ISSN 0186-7210; e-ISSN 2448-6515; doi: http://dx.doi.org/10.24201/edu.v33i2.1726 
cuando las compañías constructoras que trabajaban para Petróleos Mexicanos (Pemex) empezaron a reducir la demanda de mano de obra. Además, entre 1989 y 1990 se desplomó el precio del café, que tuvo como consecuencia el cierre del Instituto Mexicano del Café (Inmecafe), lo que afectó a miles de campesinos de la Sierra de Santa Marta (región donde se concentra el mayor número de comunidades indígenas de la entidad). En la década de los noventa desaparecieron los precios de garantía de los cultivos básicos, y en 2003 inició la liquidación del Banco Nacional de Crédito Rural (Banrural), el cual había canalizado créditos para la engorda de ganado en varios ejidos de la Sierra de Santa Marta durante los noventa. Por ello, según Velázquez (2013), fueron estas condiciones económicas las que empujaron a jóvenes indígenas de dicha región a insertarse en nuevos mercados de trabajo.

\section{San Luís Potosí}

San Luis Potosí ha sido históricamente un proveedor importante de migrantes indígenas a la ciudad de Monterrey: en 2015 dos de cada tres migrantes indígenas potosinos se trasladaron hacia esta localidad. Según Gómez (2008, p. 45), la migración indígena potosina también se debe a la necesidad de obtener un ingreso adicional a su economía de autoconsumo. Ésta fue deteriorada por las transformaciones económicas generadas en México a partir de 1980 con la implantación de políticas neoliberales en el campo. La apertura comercial en el país generó la precariedad de precios en los cultivos que producía la huasteca potosina como el café, la caña de azúcar y la naranja, así como la carencia de tierra destinada al autoconsumo. En conjunto, tales fenómenos provocaron que la población indígena de la Huasteca potosina buscara alternativas laborales fuera de la entidad. El proceso emigratorio de dicho grupo también incluye a Estados Unidos y a ciudades fronterizas como Monterrey y Nuevo Laredo. Los teenek (grupo indígena de la Huasteca potosina) se emplean generalmente en los campos agrícolas, comercio, transporte y construcción. En estas labores obtienen más ganancia, lo que implica tener acceso a mayores oportunidades de adquirir alimentos, vestidos y herramientas. "Inclusive las mujeres, que acompañan a sus esposos o padres a trabajar en cultivos que necesitaban del trabajo familiar", también se trasladan de manera individual a las ciudades de las cabeceras municipales para emplearse como trabajadoras domésticas (Hernández y Gallardo, citado por Gómez, 2008, p. 48). 


\section{Puebla}

Por su parte, el estado de Puebla es un caso paradigmático, pues en su territorio se ubica la ciudad de Puebla, considerada la cuarta ciudad más poblada de México. Al parecer no se ha constituido como lugar de atracción de migrantes indígenas poblanos, como lo ha sido la Ciudad de México; de hecho, la mitad del flujo indígena poblano tiene como destinos la Ciudad de México y el Estado de México. De acuerdo con Mora (2011, p. 57), la elección de estos lugares tiene una larga tradición que se remonta desde los años sesenta. Cuando descendieron los precios de café en los años ochenta, los migrantes indígenas comenzaron a buscar empleo en las zonas aledañas a la Central de Abastos. Con el tiempo, luego de afianzarse en diversas actividades urbanas, fueron llevándose a familiares, amigos y paisanos a trabajar a la Ciudad de México. El grupo étnico que figura en esta migración son los nahuas, cuyo flujo tomó auge ya que al migrar a la capital veían "una alternativa económica y complementaria de su actividad agrícola”.

\section{Guerrero}

En cuanto al estado de Guerrero, éste se ha caracterizado por ser un proveedor de jornaleros agrícolas a las entidades del noroeste del país, principalmente Sinaloa. En 2015 sus flujos se dirigieron hacia las entidades vecinas de Morelos, Michoacán y Estado de México. De acuerdo con Canabal (2009), la región de La Montaña guerrerense, en donde habitan poblaciones hablantes de cuatro comunidades indígenas (mixtecos, amuzgos, tlapanecos y nahuas), ha sido caracterizada como expulsora de población, misma que migra a las ciudades, los campos agrícolas o hacia Estados Unidos (al no encontrar empleo local por la escasez de tierras productivas y por el deterioro de sus recursos). La Montaña de Guerrero también es una región maicera donde se produce este grano básico para la autosubsistencia y el comercio local a pequeña escala. Asimismo, constituye una de las regiones donde no se ha invertido en obras de infraestructura y en servicios públicos, pues al haber extraído gran parte de sus recursos naturales como los bosques, su importancia económica ha disminuido, quedando como una fuente de fuerza de trabajo. De hecho, algunos de los municipios guerrerenses registran actualmente los más altos índices y grados de marginación del país, situación que ha sido determinante también para que la migración haya crecido durante las últimas décadas. De esta forma, para Canabal existe 
una elevada correlación entre los municipios con más alta intensidad migratoria y los de más altos niveles de marginación. De los 17 municipios de La Montaña, 11 son considerados como de muy alta marginación, y Metlatónoc es el municipio más pobre del país, seguido por Coicoyán de las Flores (Oaxaca) [Canabal, 2009, p. 174].

Por su parte, Rubio et al. (2000, p. 318) señalan que en La Montaña la migración ha sido una de las estrategias de sobrevivencia más importantes que la población ha adoptado. Asimismo, para estos autores el fenómeno migratorio "es complejo resultado de diferentes procesos sociales que se encuentran entrelazados". No obstante, la migración se asociaba a la crisis de la economía indígena tradicional, sustentada en la agricultura de autoconsumo y el tejido de palma.

Por su parte, estudios como los de García (2008) presentan un panorama diferente en relación a las migraciones indígenas de los nahuas del Alto Balsas, Guerrero, grupo que se ha distinguido por sus estrategias territoriales tanto a nivel nacional como internacional. Ambos flujos han coexistido de manera paralela históricamente desde mediados del siglo XX, entre la conquista de lugares comerciales para la venta de artesanías en las incipientes ciudades y centros vacacionales mexicanos, como en los destinos laborales de Estados Unidos a través del Programa Bracero (1942-1964). La autora indica que para principios del siglo XXI la amplia distribución de los nahuas se ubicaba en por lo menos cien puntos de destino migratorio en ambos países. Considera varios periodos de desplazamientos: 1940-1960, con flujos internacionales de trabajadores agrícolas e incursiones pendulares de comerciantes a ciudades del centro de México; 1970-1990, con la continuación de la emigración internacional (documentada e indocumentada) y trabajo agrícola con una fuerte expansión geográfica por el comercio de artesanías a escala nacional, encabezada por pinturas de papel amate y artesanías de factura tradicional; y 1980-2010, periodo de consolidación de "capitales migratorios internacionales" en Los Ángeles y Houston, de las migraciones circulares nacionales, al mismo tiempo que de consolidación de asentamientos en las principales ciudades como Cuernavaca (Morelos), Ciudad de México, Tijuana (Baja California), Playa del Carmen y Cancún (Quintana Roo), Mazatlán (Sinaloa), Acapulco (Guerrero), San Miguel de Allende (Guanajuato) y Los Cabos (Baja California Sur), entre otras muchas. 


\section{Yucatán e Hidalgo}

De acuerdo con los resultados de las últimas tres fuentes de información (2000, 2010 y 2015), tanto el estado de Yucatán como el de Hidalgo siguen perdiendo población, aunque en menor medida. En ambas entidades el proceso migratorio se ha diversificado generando nuevas rutas migratorias a Estados Unidos. Por otra parte, en las zonas rurales de Yucatán también se han establecido maquiladoras, las cuales han ocupado una fuerza laboral "abundante, dócil y barata", ya que los sueldos representan la mitad de los salarios que percibe un operario en las maquiladoras de la frontera norte (Iglesias, 2011).

En el caso de Hidalgo, uno de los factores que explica el descenso de la migración interna es que los HLI, especialmente los otomíes del Valle del Mezquital, encontraron en la migración internacional su principal ruta migratoria, la cual se intensificó durante los noventa y alcanzó su máximo apogeo en la década siguiente (Rivera y Quezada, 2011). De esta forma, los otomíes de Hidalgo dejaron a un lado la movilidad histórica que tenían hacia la Ciudad de México, que si bien continúa, ya no es con la misma intensidad que tuvo durante las décadas de los sesenta y los ochenta. No obstante, los nahuas de la Huasteca (el grupo indígena mayoritario en Hidalgo) son quienes siguen movilizándose hacia otras entidades distintas de la Ciudad de México, como Jalisco y Nuevo León.

En este apartado hemos resaltado aquellas entidades que perdieron más población en 2015. En esta somera descripción de la literatura de quienes han profundizado sobre los grupos indígenas de estas entidades, podemos identificar la permanencia de algunas causas estructurales de estas migraciones indígenas que otrora señalara Rubio et al. (2001). Entre ellas se encuentran: la desventajosa relación que la sociedad nacional había mantenido históricamente con las etnias, el deterioro ecológico de sus territorios, la presión demográfica sobre la tierra, el caciquismo y la expoliación, y los conflictos políticos y sociales. A esto añadiríamos otras causas estructurales producto de la recomposición de la economía mundial, como la caída de los precios internacionales del café, los desastres naturales, una economía agrícola altamente tecnificada de empresas transnacionales como las asentadas en el noroeste del país, los corredores turísticos como los de la Península de Yucatán, entre otros. Dadas las condiciones de violencia imperante en el país, es posible que las migraciones interestatales en el futuro estén marcadas por esta coyuntura. 


\section{Conclusiones}

En este documento identificamos que la migración indígena presenta dos patrones migratorios predominantes: rural-urbano y rural-rural. En el primero vemos que las grandes zonas metropolitanas como Monterrey, Guadalajara y la Ciudad de México continúan siendo los principales receptores de migrantes indígenas en el país. Sin embargo, las transformaciones espaciales que han sufrido estas zonas en las últimas décadas, como la expansión territorial más allá de sus municipios históricos, han provocado que en los años recientes los nuevos migrantes indígenas no se concentren en estos municipios históricos, sino cada vez más se agrupen en los periféricos; tal es el caso de los municipios conurbanos de la Ciudad de México, Zapopan (en Guadalajara) y los municipios de Juárez, García, Santa Catalina y Escobedo (en Monterrey). De igual manera, estas transformaciones revelan que en los municipios centrales de las grandes zonas metropolitanas ha disminuido el asentamiento de la población indígena; el costo de la vivienda en estos municipios podría explicar tal situación. Estas aglomeraciones urbanas presentan una gran diversidad de empleos, por tanto, hay una gran heterogeneidad laboral, principalmente en actividades de comercio y servicios. Esta población indígena no se especializa en ninguna actividad en la ciudad, aunque si bien una pequeña proporción continúa insertándose en los trabajos domésticos, éstos no son los más importantes. Estas ciudades tradicionales no son actualmente los únicos sitios de atracción de los migrantes indígenas, también se han consolidado otros espacios como las ciudades de sol y playa de Quintana Roo, y las ciudades fronterizas como Tijuana, en Baja California. En las ciudades de Quintana Roo las actividades turísticas permiten una rápida inserción de este grupo de población; sin embargo, Tijuana, con gran demanda de empleo maquilador, hace posible que este grupo de población se emplee en actividades manufactureras.

En cuanto al segundo patrón migratorio, se trata de migrantes indígenas que han encontrado un nicho laboral en las actividades agropecuarias, principalmente en los estados de Sinaloa y Baja California. Recientemente, Jalisco también se ha vuelto un estado receptor importante de tal flujo. Este grupo de población indígena es el más vulnerable, pues la migración jornalera se ha convertido en una estrategia familiar, y las empresas agrícolas se han valido de la necesidad de ingresos en las regiones indígenas para ofrecer condiciones de trabajo precarias relacionadas con el origen étnico y la escasa calificación formal (Canabal, 2016). Mientras los rezagos sociales continúen en las entidades con población indígena, éstas continuarán expulsando población pues las condiciones de pobreza y marginación no se terminarán 
en el corto plazo, más bien se han agravado. Por ello, para una gran parte de la población indígena la migración es la única vía para poder satisfacer sus necesidades más esenciales como alimento y vestido.

Por último, los resultados indican que la migración indígena ha estado disminuyendo, al igual que la de los no indígenas; esto nos indica que ambas migraciones están vinculadas a las dinámicas económicas y sociales del país. Un trabajo interesante por hacer en el futuro sería conocer por qué se ha dado esta disminución en ambas poblaciones. Finalmente, otro dato que nos llama la atención es que la Ciudad de México se volvió un lugar expulsor de migrantes, lo que nos podría dar indicio de un nuevo patrón migratorio en los indígenas migrantes: urbano-urbano.

\section{Anexo}

\section{Cuadro A1}

Saldo neto migratorio por lugar de residencia de la población hablante de alguna lengua indígena, 1990

\begin{tabular}{lrlr}
\hline Entidad & Saldo & Entidad & Saldo \\
\hline Quintana Roo & 18470 & Coahuila & 186 \\
México & 15087 & Aguascalientes & 146 \\
Sinaloa & 11608 & Durango & 98 \\
Baja California & 6727 & Campeche & 78 \\
Ciudad de México & 3996 & Zacatecas & 63 \\
Jalisco & 2960 & Sonora & 42 \\
Veracruz & 2591 & Guanajuato & -32 \\
Tamaulipas & 2381 & Tlaxcala & -299 \\
Morelos & 1998 & Michoacán & -701 \\
Nuevo León & 1483 & San Luis Potosí & -1391 \\
Colima & 743 & Chiapas & -3416 \\
Baja California Sur & 737 & Puebla & -4208 \\
Tabasco & 717 & Hidalgo & -5073 \\
Querétaro & 542 & Guerrero & -7083 \\
Nayarit & 446 & Yucatán & -15074 \\
Chihuahua & 403 & Oaxaca & -34227 \\
\hline
\end{tabular}

Fuente: Elaboración propia con base en el 1\%, Censo de Población y Vivienda 1990. 


\section{Cuadro A2}

Saldo neto migratorio por lugar de residencia de la población hablante de alguna lengua indígena, 2000

\begin{tabular}{lrlr}
\hline Entidad & Saldo & Entidad & Saldo \\
\hline México & 17592 & Tabasco & 518 \\
Sinaloa & 16049 & Aguascalientes & 523 \\
Quintana Roo & 11230 & Colima & 437 \\
Baja California & 7921 & Zacatecas & 195 \\
Nuevo León & 6532 & Durango & 193 \\
Ciudad de México & 6458 & Baja California Sur & 58 \\
Tamaulipas & 5959 & Querétaro & 20 \\
Jalisco & 3096 & Michoacán & -376 \\
Morelos & 2329 & Puebla & -3550 \\
Sonora & 2265 & Hidalgo & -3592 \\
Chihuahua & 2213 & Chiapas & -4796 \\
Tlaxcala & 964 & San Luis Potosí & -5921 \\
Guanajuato & 928 & Yucatán & -7356 \\
Coahuila & 749 & Veracruz & -13551 \\
Campeche & 599 & Guerrero & -16591 \\
Nayarit & 581 & Oaxaca & -31670 \\
\hline
\end{tabular}

Fuente: Elaboración propia con base en el Cuestionario Ampliado del XII Censo de Población y Vivienda. 


\section{Cuadro A3}

Saldo neto migratorio por lugar de residencia de la población hablante de alguna lengua indígena, 2010

\begin{tabular}{lclc}
\hline Entidad & Saldo & Entidad & Saldo \\
\hline Nuevo León & 9141 & Zacatecas & 315 \\
Quintana Roo & 8868 & Coahuila & 169 \\
México & 8414 & Durango & 125 \\
Baja California & 4335 & Campeche & -390 \\
Jalisco & 3708 & Colima & -404 \\
Tamaulipas & 3124 & Michoacán & -1061 \\
Morelos & 2425 & Ciudad de México & -1327 \\
Baja California Sur & 1884 & Sinaloa & -1495 \\
Chihuahua & 1489 & Hidalgo & -2068 \\
Tabasco & 1375 & Yucatán & -3009 \\
Querétaro & 1358 & Guerrero & -3560 \\
Aguascalientes & 1340 & Puebla & -4965 \\
Tlaxcala & 1137 & San Luis Potosí & -5335 \\
Guanajuato & 704 & Veracruz & -5492 \\
Nayarit & 375 & Chiapas & -10528 \\
Sonora & 339 & Oaxaca & -10992 \\
\hline
\end{tabular}

Fuente: Elaboración propia con base en el Cuestionario Ampliado del XII Censo de Población y Vivienda. 


\section{Cuadro A4}

Saldo neto migratorio por lugar de residencia de la población hablante de alguna lengua indígena, 2015

\begin{tabular}{lrlc}
\hline Entidad & $\boldsymbol{S N M}$ & Entidad & SNM \\
\hline Quintana Roo & 13028 & Aguascalientes & 407 \\
Nuevo León & 11209 & Coahuila & 358 \\
Sinaloa & 8140 & Zacatecas & 275 \\
México & 7881 & Chihuahua & -171 \\
Baja California & 3324 & Durango & -292 \\
Jalisco & 2870 & Tamaulipas & -607 \\
Tabasco & 2502 & Michoacán & -616 \\
Baja California Sur & 2366 & Hidalgo & -1338 \\
Morelos & 1903 & Ciudad de México & -2435 \\
Querétaro & 1645 & Puebla & -2519 \\
Guanajuato & 1307 & Yucatán & -3307 \\
Sonora & 1171 & San Luis Potosí & -5073 \\
Tlaxcala & 916 & Veracruz & -6138 \\
Campeche & 840 & Guerrero & -8470 \\
Nayarit & 799 & Oaxaca & -14866 \\
Colima & 425 & Chiapas & -15534 \\
\hline
\end{tabular}

Fuente: Elaboración propia con base en el Cuestionario Ampliado de la Encuesta Intercensal 2015 .

\section{Bibliografía}

Canabal, Beatriz (2009). Migración indígena. El caso de Guerrero. Veredas, 18, 85126. Recuperado de http://bidi.xoc.uam.mx/MostrarPDF.php

Canabal, Beatriz (2016). Migración interna y nuevos actores sociales. En Beatriz Canabal y Martha Angélica Olivares Díaz (eds.). Sujetos rurales. Retos y nuevas perspectivas de análisis (pp. 193-212). México: UAM-Xochimilco.

Canabal, Beatriz y Olivares Díaz, Martha Angélica (eds.). (2016). Sujetos rurales. Retos y nuevas perspectivas de análisis. México: UAM-Xochimilco.

Cárdenas, Erika (2014). Migración interna e indígena en México: enfoques y perspectivas. Intersticios Sociales, 7, 1-28. Recuperado de http://www.redalyc.org/ articulo.oa? $\mathrm{id}=421739500003$

Chávez, Ana (1999). La nueva dinámica de la migración interna en México de 1970 a 1990. México: UNAM-CRIM. 
Chávez, Ana (2009). La migración interna en México. En Luz María Valdez (coord.), Derecho de los mexicanos: introducción al derecho demográfico (pp. 267-282). México: UNAM, Instituto de Investigaciones Jurídicas. Recuperado de http:// bibliohistorico.juridicas.unam.mx/libros/6/2638/14.pdf

Consejo Nacional de Población (2012). Índice de marginación por entidad federativa y municipio 2010. Ciudad de México: Conapo. Recuperado de http://www. conapo.gob.mx/en/CONAPO/Indices_de_Marginacion_2010_por_entidad_ federativa_y_municipio

Corona, Rodolfo y Serrano, Arcelia (2010). Cuantificación y perfil sociodemográfico de los hogares con condición indígena en el municipio de Tijuana. En Laura Velasco, Rodolfo Corona, Marie Laure Coubés Ravaille y Rafaél Vela Gonzales (coords.), Tijuana indígena: estudio sobre las condiciones de vida e integración social de la población indígena a la ciudad. México: Comisión Nacional para el Desarrollo de los Pueblos Indígenas.

Durin, Séverine (2003). Nuevo León, un nuevo destino de la migración indígena, Antropología Experimental, 3, 1-7. Recuperado de https://revistaselectronicas. ujaen.es/index.php/rae/article/view/2103

Durin, Séverine (2006). Ser una mujer indigena en Monterrey. Fragmentos de tres historias de vida. Trabajo presentado en el Foro Migración Indígena, de la Comisión para el Desarrollo de los Pueblos Indígenas, Ciudad de México. Recuperado de http://www.cdi.gob.mx/sicopi/migracion_oct2006/4_ser_una_mujer_ indigena_en_monterrey_severine_durin.pdf

Durin, Séverine (2008). Entre luces y sombras. Mirada sobre los indígenas en el Área Metropolitana de Monterrey. México: CIESAS, CDI.

Durin, Séverine, Moreno, Rebeca y Sheridan, Cecilia (2007). Rostros desconocidos. Perfil sociodemográfico de las indígenas en Monterrey. Trayectorias, 9(23), 29-42. Recuperado de http://www.redalyc.org/pdf/607/60715117005.pdf

Fernández, Patricia (2011). Las identidades étnicas en México. Este País. Tendencia y Opiniones. Recuperado de: http://estepais.com/site/?p=33528

García, Martha (2007). Migraciones del Alto Balsas. Regiones, 30, 2-4. Recuperado de http://suplementoregiones.com/pdf/Regiones30.pdf

García, Martha (2008). Dimensiones simbólicas de la inmigración indocumentada. Rituales de paso de "norteños" y "norteñas" nahuas del sur de México hacia Estados Unidos. Norteamérica, 3(1), 121-152. Recuperado de http://www.revista norteamerica.unam.mx/index.php/nam/article/view/64

García, Martha (2013). Migraciones laborales, derechos humanos y cooperación internacional: cortadores de caña centroamericanos en la frontera México-Belice. Trace, 63, 7-23. Recuperado de https://trace.revues.org/971

García, Martha y Frédéric Décosse (2014). Agricultura intensiva y políticas de migración laboral: jornaleros centroamericanos en México y marroquíes en Francia. Migración y Desarrollo, 12(23), 5-31. Recuperado de https://hal.archivesouvertes.fr/halshs-01146720/document

Gómez, Lizbeth (2008). “Vámonos pa'l jale”. Enganche, contratación y contratistas

Estudios Demográficos y Urbanos, vol. 33, núm. 2 (98), 2018, pp. 327-363

ISSN 0186-7210; e-ISSN 2448-6515; doi: http://dx.doi.org/10.24201/edu.v33i2.1726 
en el sur de la Huasteca Potosina (tesis de maestría, El Colegio de San Luis, San Luis Potosí, México).

Granados, José (2005). Las nuevas zonas de atracción de migrantes indígenas en México. Investigaciones Geográficas, 58, 140-147. Recuperado de http://www. scielo.org.mx/pdf/igeo/n58/n58a9.pdf

Granados, José (2009). El impacto de la reestructuración económica en los procesos migratorios en Sinaloa, 1985-2005. Región y Sociedad, 21(45), 205-226. Recuperado de http://www.redalyc.org/articulo.oa?id=10211819008

Hernández, Rafael (2014). Ser indígena en una cuadrilla de blancos. Migración y trabajo agrícola racializado en la era de la globalización. Universitas Humanistica, 77, 197-223. Recuperado de http://www.redalyc.org/articulo.oa?id= 79130107009

Iglesias, Esther (2011). Las nuevas migraciones yucatanenses: territorios y remesas. Migración y Desarrollo, 9(17). Recuperado de http://www.scielo.org.mx/scielo. php?script=sci_arttext\&pid=S1870-75992011000200003\&lng=es\&nrm=iso

INEGI (1990). XI Censo General de Población y Vivienda, 1990. México: Instituto Nacional de Estadística y Geografía. Recuperado de http://www.beta.inegi.org. $\mathrm{mx} /$ proyectos/ccpv/1990/default.html

INEGI (2000). XII Censo General de Población y Vivienda, 2000. México: Instituto Nacional de Estadística y Geografía. Recuperado de http://www.beta.inegi.org. $\mathrm{mx} /$ proyectos/ccpv/2000/default.html

INEGI (2010). Censo de Población y Vivienda, 2010. México: Instituto Nacional de Estadística y Geografía. Recuperado de http://www.beta.inegi.org.mx/proyectos/ ccpv/2010/

INEGI (2015). Encuesta Intercensal 2015. México: Instituto Nacional de Estadística y Geografía. Recuperado de http://www.beta.inegi.org.mx/proyectos/enchogares/ especiales/intercensal/

Martínez, Germán (2013). Migración internacional chiapaneca: trayectorias de movilidad, sociodemográficas, y condiciones sociales. Pueblos y Fronteras, 8(15), 50-91. Recuperado de http://www.redalyc.org/pdf/906/90627463003.pdf

Mora, Libertad (2011). Dinámicas migratorias en Pahuatlán: municipio de indígenas y mestizos de la Sierra Norte de Puebla (1980-2010) (tesis de maestría, CIESAS, México).

Partida, Virgilio (2000a). Migración interna. En Brígida García y Manuel Ordorica (coords.), Los grandes problemas de México: Población. (pp. 325-362). México: El Colegio de México, A.C.

Partida, Virgilio (2000b). La migración interestatal de la población indígena entre 1985 y 1990 [recuadro]. En INI, PNUD (ed.), Estado del desarrollo económico y social de los pueblos indígenas de México. Primer informe (tomo 1) (pp. 295301). México: INI, PNUD.

Pérez, Enrique y Santos, Clemencia (2013). Tendencias recientes de la migración interna en México. Papeles de Población, 76, 53-88. Recuperado de: http:// www.redalyc.org/articulo.oa?id=11227645003 
Rangel Rigotti, José Irineu (2009). Información de los censos demográficos del Brasil sobre migraciones internas: críticas y sugerencias para el análisis. Notas de Población, 36(88), 219-244. Recuperado de http://archivo.cepal.org/pdfs/ NotasPoblacion/NP88Rangel.pdf

Rivera, Guadalupe y Quezada, María (2011). El Valle del Mezquital, estado de Hidalgo. Itinerario, balances y paradojas de la migración internacional de una región de México hacia Estados Unidos. Trace, 60, 85-101. Recuperado de https://trace.revues.org/1757

Rivera, Liliana (2007). La formación y dinámica del circuito migratorio MixtecaNueva York-Mixteca: los trayectos internos e internacionales. Norteamérica, 2(1), 171-203. Recuperado de http://www.redalyc.org/articulo.oa?id= 193715169007

Rubio, Miguel Ángel et al. (2000). Desarrollo, marginalidad y migración. En INI, PNUD (ed.), Estado del desarrollo económico y social de los pueblos indígenas de México. Primer informe (tomo 1). México: INI, PNUD.

Santos, Rosa y García, Martha (2015). Perfil sociodemográfico de las familias jornaleras de origen guatemalteco empleadas en el cultivo de caña en la región azucarera de La Joya, Campeche. En María Félix Quezada (coord.), Migraciones indigenas (pp. 147-180). México: Universidad Autónoma del Estado de Hidalgo.

Serrano, Enrique (2005). La población indígena a través de los censos mexicanos. En Pueblo indígenas y afrodescendientes de América Latina y el Caribe: información sociodemográfica para políticas y programas. Santiago, Chile: CEPAL. Recuperado de https://www.cepal.org/celade/noticias/paginas/7/21237/ESerrano.pdf

Sobrino, Jaime (2013). Dinámica de la migración interna en México en la primera década del nuevo milenio (pp. 201-2015). México: UNAM, Instituto de Investigaciones Jurídicas. Recuperado de http://bibliohistorico.juridicas.unam.mx/ libros/8/3538/12.pdf

Valdés, Luz María (2003). Comentarios y reflexión acerca de la identificación de la población indígena en los censos mexicanos. En François Lartigue y André Quesnel (coords.), Las dinámicas de la población indígena. Cuestiones y debates actuales en México. México: CIESAS / Porrúa.

Valencia, Alberto (2000). La migración indígena a las ciudades. México: Instituto Nacional Indigenista / Programa de Naciones Unidas para el Desarrollo.

Vázquez, Alejandro y Prieto, Diego (2012). Indios en la ciudad. Identidad, vida cotidiana e inclusión de la población indígena en la metrópoli queretana. México: INAH/UAQ.

Vázquez, Germán y Quezada, María (2015). Los indígenas autoadscritos de México en el Censo 2010: ¿revitalización étnica o sobreestimación censal? Papeles de Población, 21(86), 171-218. Recuperado de http://www.scielo.org.mx/pdf/pp/ v21n86/v21n86a7.pdf

Velasco, Laura (2007). Migraciones indígenas a las ciudades de México y Tijuana. Papeles de Población, 13(52), 183-209. Recuperado de http://www.scielo. org.mx/pdf/pp/v13n52/v13n52a7.pdf 
Velasco, Laura (2011). Identidad regional y actores: una experiencia de intervención sociológica en el Valle de San Quintín, Baja California. Economía, Sociedad y Territorio, 51, 43-70. Recuperado de http://www.redalyc.org/articulo.oa?id= 10220221002

Velázquez, Emilia (2013). Migración interna indígena desde el Istmo veracruzano: nuevas articulaciones regionales. LiminaR, 11(2), 128-148. Recuperado de http:// www.scielo.org.mx/scielo.php?script $=$ sci_arttext\&pid $=\mathrm{S} 1665-8027201$ 3000200009\&lng=es\&nrm=iso. ISSN 2007-8900.

Villafuerte Daniel y García, María del Carmen (2014). Tres ciclos migratorios en Chiapas: interno, regional e internacional. Migración y Desarrollo, 22(12), 5-37. Recuperado de http://www.scielo.org.mx/pdf/myd/v12n22/v12n22a1.pdf

\section{Acerca de los autores}

José Aurelio Granados Alcantar es doctor en Planificación Territorial y Desarrollo Regional por la Universidad de Barcelona, maestro en Demografía por El Colegio de la Frontera Norte, y licenciado en Economía por la Universidad Autónoma de Sinaloa. Actualmente es profesor investigador de la Universidad Autónoma del Estado de Hidalgo (UAEH), donde también funge como coordinador del Doctorado en Ciencias Sociales. Es miembro del Sistema Nacional de Investigadores, nivel I. Sus líneas de investigación son migración y demografía étnica. Entre sus publicaciones más recientes sobresalen: "Los nuevos escenarios de la migración internacional indígena en México" (en coautoría con María Félix Quezada Ramírez), en Laura L. Rodríguez y Jhon Antón (orgs.), La población afrodescendiente e indígena en América Latina. Puntos de reflexión para el debate sobre Cairo +20 , Belo Horizonte, Brasil, ALAP, (Investigaciones, 4), 2014; "Migración y movilidad laboral entre las zonas metropolitanas de la Región Centro de México" (en coautoría con Myriam Franco Sánchez), Papeles de Población, núm. 91, 2017.

María Félix Quezada Ramírez es doctora en Estudios del Desarrollo por la Universidad Autónoma de Zacatecas, maestra en Demografía por El Colegio de la Frontera Norte, y licenciada en Sociología por la Universidad Autónoma Metropolitana, Unidad Xochimilco. Actualmente es profesora investigadora de la Universidad Autónoma del Estado de Hidalgo (UAEH), donde también funge como coordinadora del Doctorado en Estudios de Población. Es miembro del Sistema Nacional de Investigadores, nivel I. Sus líneas de investigación son la demografía étnica, la migración indígena y el 
desarrollo indígena. Entre sus publicaciones más recientes sobresalen: "Los indígenas autoadscritos de México en el Censo 2010: revitalización étnica o sobreestimación censal" (en coautoría con Germán Vázquez Sandrín), Papeles de Población, núm. 86, 2015; "Los nuevos escenarios de la migración internacional indígena en México" (en coautoría con José Aurelio Granados Alcantar), en Laura L. Rodríguez y Jhon Antón (orgs.), La población afrodescendiente e indígena en América Latina. Puntos de reflexión para el debate sobre Cairo +20 , Belo Horizonte, Brasil, ALAP (Investigaciones, 4), 2014.

Fecha de recepción: 25 de enero de 2017.

Fecha de aceptación: 16 de noviembre de 2017. 
